\title{
- ST segment elevation myocardial infarction caused by distal right coronary artery embolism due to atrial fibrillation: a case report
}

\author{
Ivana Jurin*, \\ Mario Sičaja, \\ Tomo Svaguša, \\ Sandra Jakšić \\ Jurinjak, \\ Diana Rudan, \\ Orzal Hadžibegović, \\ Boris Starčević
}

University Hospital Dubrava, Zagreb, Croatia
KEYWORDS: atrial fibrillation, ST segment elevation myocardial infarction, coronary artery embolism. CITATION: Cardiol Croat. 2017;12(9-10):347. I https://doi.org/10.15836/ccar2017.347

*ADDRESS FOR CORRESPONDENCE: Ivana Jurin, Klinička bolnica Dubrava, Avenija Gojka Šuška 6, HR-10000 Zagreb, Croatia. / Phone: +385-98-559-387 / E-mail: ivana.sakic@yahoo.com

ORCID: Ivana Jurin http://orcid.org/0000-0002-2637-9691 • Mario Sičaja http://orcid.org/0000-0003-0773-4720 Tomo Svaguša http://orcid.org/0000-0002-2036-1239 • Sandra Jakšić Jurinjak http://orcid.org/0000-0002-7349-6137 Diana Rudan http://orcid.org/0000-0001-9473-2517 • Irzal Hadžibegović http://orcid.org/0000-0002-3768-9134 Boris Starčević http://orcid.org/0000-0002-3090-2772

IIIIIIIIIIIIIIIIIIIIIIIIIIIIIIIIIIIIIIIIIIIIIIIIIIIIIIIIIIIIIIIIIIIIIIIIIIIIIIIIIIIIIIIIIIIIIIIIIIIIIIIIIIIIIIIIIIIIIII

Background: Nonvalvular atrial fibrillation (AF) is the most common cause of systemic embolism. In rare cases, AF can cause coronary artery embolism which is a rare but important nonatherosclerotic cause of acute myocardial infarction. ${ }^{1}$

Case report: We report the case of 81-years-old man with permanent atrial fibrillation who presented to our hospital with ST segment elevation myocardial infarction. Coronary angiography verified the embolic occlusion of distal posterolateral branch, which is a branch of the right coronary artery, unsuitable for percutaneous coronary intervention, and no significant atherosclerotic coronary artery disease was found. Transthoracic echocardiography showed a slightly reduced left heart systolic function (EF 45-50\%), higher grade diastolic dysfunction and reduced longitudinal strain in inferoposterior segments of left ventricle (-2 to -7). The patient was treated according to the current guidelines.

Conclusion: Proper anticoagulant therapy in patients with atrial fibrillation is extremely important in order to prevent thrombus formation, and consequently, the embolism commonly occurring in these conditions. Echocardiographic measurement of the longitudinal strain could indicate a greater possibility of forming the thrombus in patients with impaired cardiac contractility. At present, measurement of the ventricular strain is recommended as a better method for estimating the systolic function from the measurement of the ejection fraction. Using this method, it is better to examine segmental mobility of individual parts of the ventricle and to better evaluate contractility. Also, the strain may point to the hipo(a)contractility of the ventricle. In this case, there is a possibility that in this negligible part of the ventricle, conditions for the thrombus formation were created. Is this the case in this patient we cannot safely claim. Research is needed to confirm this assumption.
RECEIVED:

September 9, 2017

ACCEPTED:

September 26, 2017

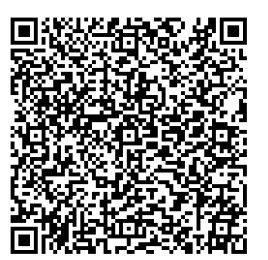

LITERATURE IIIIIIIIIIIIIIIIIIIIIIIIIIIIIIIIIIIIIIIIIIIIIIIIIIIIIIIIIIIIIIIIIIIIIIIIIIIIIIIIIIIIIIIIIIIIIIIIIIIIIIIIIIIIII

1. Shibata T, Kawakami S, Noguchi T, Tanaka T, Asaumi Y, Kanaya T, et al. Prevalence, Clinical Features, and Prognosis of Acute Myocardial Infarction Attributable to Coronary Artery Embolism. Circulation. 2015 Jul 28:132(4):241-50. https://doi.org/10.1161/CIRCULATIONAHA.114.015134 